\title{
Development of human potential as an important condition of the economic security of the enterprise
}

\author{
Ekaterina Viktorovna Gomeleva ${ }^{1}$, Lyudmila Gennad'evna Ripoll-Saragosi ${ }^{1}$, \\ Viktoriia Sergeevna Kokhanova ${ }^{2}$, and Natalia Stanislavovna Grigorieva ${ }^{2}$ \\ ${ }^{1}$ Rostov State Transport University, square of the Rostov, Rostov-on-Don, Russia \\ ${ }^{2}$ Private Educational Institution of Higher Education"SOUTHERN UNIVERSITY (IMBL)", Rostov- \\ on-Don, Russia
}

\begin{abstract}
The main concept of the study is based on the study of human potential as one of the conditions for the economic security of an enterprise. The article considers the theoretical aspects of human potential, describes the subject of human potential, reveals assessment tools and factors influencing its human development. The most significant potential threats that directly affect the development of human potential are indicated, including: the risk of burnout of employees working remotely, the prevalence of relatively directive management methods at the level of line managers of the enterprise. The ways of overcoming the existing problems are proposed, the solution of which will influence the development of human potential.
\end{abstract}

\section{Introduction}

Human potential and its development in the modern world is increasing its role every year. The statement "Human resources is key" shows that both the development of an enterprise and the possibility of its bankruptcy depend on the personnel. According to many experts, a person is the most difficult link in the security system, since it is the human factor that can have a critical impact on the success of the activity and the existence of the company itself. Employees are one of the most promising and inexhaustible resources of an enterprise that determine its efficiency and success. After all, it is people who play the first fiddle in business processes - they process information, make decisions, and are directly involved in the production process. Their competence and correctness of actions directly depends on how efficiently the means of production and other resources are used at the enterprise, and how successfully the enterprise as a whole works. Competent personnel management is a contribution to the future income of an organization by providing the enterprise with highly qualified and motivated employees, effectively using their potential, skill and creative capabilities, and meeting their social needs. One of the goals of economic security in terms of personnel management is the selection of qualified personnel with high potential, its effective use and development, as well as minimization of risks and threats from employees. To ensure the economic security of an economic entity, its personnel policy 
should be structured in such a way that the development of human potential is one of the priority tasks.

Theoretical and conceptual aspects of human potential and its development were the subject of scientific research by Russian scientists: Avdeeva E., Babina S.; B urkalcevoy D. Davydova T., A. Kazarcevoy Makeeva T., Mishchenko V., Nesterova A., Plaksa S., Reznikova O., Sadovnikova I., Sirotkina N. and a number of others who proposed different approaches to the study of economic phenomena and human potential that affects economic security, and also foreign scientists Amartya Kumar Sen, Tokatly H.,; Dorneich, MC; Moran, S., Krustik F., Kechek D., Polgar I., Gardner H., Dai D. and others.

The topic of human development as an important condition for the economic security of an enterprise has recently become a trend in the modern economy, so the choice of a research topic is relevant.

\section{Research methodology}

The studies carried out show that Russian economists do not have a unified approach to the definition of "human potential". In addition, there is no unambiguous understanding of what human potential is. In different sources, there are different interpretations: "human factor", human capital assets, human resources potential assets, labor potential assets, etc. In general, Human potential assets is the ability of an individual (a set of individuals) to show theoretical capabilities in practice $[1,2,3,4]$.

A number of authors believe that human potential assets should be understood as the qualities of people (a person) that fundamentally affect the results of the activity in which they are involved in a particular sphere (area) of activity [5, 6, 7]. From the standpoint of the authors of this study, it is interesting and quite complete to consider the definition of human potential in the context of the economic security of an enterprise, namely, certain qualitative characteristics and potential capabilities of an employee, which have a fundamental impact on the effectiveness of his production activities in a certain area of the economy.

The research carried out made it possible to single out a tool for assessing human potential - competence $[2,5,8]$. The most important key competencies of human potential assets, which play a decisive role in ensuring the success of an organization, include the following: learning ability - the ability to use, create, save, transfer new knowledge; flexibility, adaptability - the ability to quickly rebuild without losing its integrity and identity; leadership - the ability to inspire and lead; communication skills - the ability to build communications both within the organization (between colleagues, between management and personnel, etc.) and outside the organization; innovativeness - the ability to use creative potential to find new solutions, rationalization proposals, improvements, etc. $[3,4,9,10]$.

So how is it possible to identify high-potential employees? A successful employee showing good work results does not always have high potential, which gives him the opportunity in the future to successfully realize himself in new projects and roles. In modern companies, effective employees are divided into highly productive (High Professionals - HiPro) and high potential (High Potential - HiPo) [11]. The former are highly effective in their current role. The latter also show good results, but this is not their limit, since their internal potential can be much wider than the demonstrated one, and they are able to master new functionality faster than others to be successful when changing their role. As mentioned above, such employees can quickly adapt and be involved in performing tasks from a new direction of professional activity without special difficulties, work effectively in multitasking mode, are distinguished by creativity and the ability to non- 
standard problem solving. They have pronounced leadership and organizational skills, as well as the desire and readiness for continuous development and self-improvement.

To attract, retain and motivate HiPo employees, it is necessary to create an effective system for the identification, support and development of talents in the organization. Highpotential employees should be treated with particular care by the company's management, including investing in their development. The implemented personnel policy should be aimed at forming a special system for working with HiPo in order to develop it, including the following tools:

- the use of modern methods, tools and approaches in the selection and selection of personnel, both in the labor market when filling vacancies, and in the formation of the organization's personnel reserve;

- maintaining the professional level of knowledge and skills of employees for effective work, taking into account the need to solve both current and future business problems;

- informing employees about the development strategy of the enterprise, its structure and technology of activity, involving personnel at the stage of formulating business goals, thereby creating and maintaining a sense of involvement in the activities of the organization;

- ensuring an adequate level of income for workers and strengthening the incentive role of payment for work;

- implementation of diverse programs for the development of professional, personal and managerial competencies and analysis of changes in the competencies of employees after each training;

- development of individual plans for the development of talents, taking into account their potential and needs for self-realization, conducting regular assessment interviews for developmental feedback;

- preparation of employees for potential relocation or promotion, possible replacement of colleagues on vacation, business trip, absence due to illness, etc.;

- implementation of various stimulating and motivational programs aimed at maintaining a positive attitude in employees towards the work performed and increasing interest in the results of their work;

- development of social programs stimulating an increase in personnel loyalty and satisfaction with working conditions.

In the context of ensuring the economic security of enterprises, it is important to establish the most significant potential threats that directly affect the development of human potential and, accordingly, the level of economic security of enterprises. These, in our opinion, include:

- $\quad$ First, the risk of burnout for telecommuters can be identified.

- secondly, the problem may be the prevalence of relatively directive management methods at the level of line managers of the enterprise.

The study of the above threats is extremely important in the modern conditions of society.

\section{Research results}

Examining the external and internal factors of the emergence of threats to the economic security of the enterprise, the management, the personnel management service in the development of the main directions of personnel policy should be guided by the timely determination of personnel needs, both in quantitative and qualitative aspects, to apply current forms of attracting and further use of human potential, to carry out activities on the 
timely identification of factors affecting the effectiveness of the use of human potential assets.

Based on the results of the study of factors affecting human development, one of the most significant potential threats was substantiated is the risk of burnout of employees working remotely $[1,12]$.

In connection with the introduction of a self-isolation regime associated with the coronavirus pandemic, office workers were urgently transferred to work from home in April 2020. Modern technologies allowed the company to quickly and successfully organize work from home and business managed to cope with the forced massive transition to remote work. At the same time, as an advantage for the organization, it can be noted a decrease in the costs of maintaining and servicing the office, delivering employees to the enterprise on corporate buses, etc. Employees also saw a number of advantages in the remote work : saving time on commuting to the office, reducing the number of distractions when working in the office, and more. The productivity of employees in performing current tasks (analyzing data, preparing reports and presentations, etc.) remained at the same level, and sometimes even increased slightly due to the high pace of work in a crisis. However, over time, certain problems associated with telecommuting began to appear: the home became a permanent workplace, and for many it turned out to be more difficult than it seemed earlier [13].

To solve the existing problem, it is proposed to implement an additional set of activities at the enterprise.

Due to the fact that the office for employees has become their home, the boundaries of "work-home" have been erased, and even with fewer tasks, they can appear at any time in an e-mail or communicator. At the same time, no one set the task for employees to stay in touch around the clock, for the most part this is their independent decision, due to the blurring of the boundaries separating work and home, their loyalty and a high sense of responsibility. One of the activities to mitigate this problem is prioritizing and scheduling cases in terms of importance and urgency, establishing a clear daily plan of the day in an online calendar with obligatory breaks for lunch and rest. It allows to visualize tasks and distribute the charge. It can be used the "Tomato Method" by Francesco Cirillo, when 25 minutes are allocated for solving current problems, and then a break is taken for 3-5 minutes; to keep track of time, a regular timer or special applications are used [14]. It is also necessary to take breaks from online meetings to complete work tasks: close email and all communicators at the scheduled time and work on a specific task. Otherwise, the whole day will be spent on small questions and meetings, and you will have to work at night when no one is distracting.

To solve production issues with colleagues, it is proposed to give preference to phone calls or communication in communicators with the inclusion of video communication (Teams, Zoom, etc.), rather than correspondence by e-mail or in a communicator, because emotions are not visible in the chat. Since you have incomplete communication without verbal contact, there is a chance to miss something. Without seeing each other, it is difficult to understand what kind of person is, what his look and intonation is, what gestures the interlocutor has at the moment, or how he changes poses. Moreover, not everyone use the same terms, concepts, etc. Therefore, more efforts are spent to understand what information they want to convey, internal instincts are turned on, which make you think out the situation and not always in the right direction.

The lack of personal contact with the manager worries many employees that their professional efforts will go unnoticed. Timely face-to-face communication is the main way to deal with burnout. It is very important to be able and practice to express your concerns, objections, worries orally and discuss them. Therefore, in addition to general meetings, managers are advised to regularly hold individual online meetings with subordinate 
employees to discuss their success, difficulties in work and personal communication. It is also necessary to discuss and plan the training and development of employees, their participation in any projects, since a person physically sits in one place at home, and it seems to him that there has been a pause in his development. All this will help employees gain confidence, and managers can track changes in mood in time and jointly develop a solution plan.

For informal communication with colleagues, you can envisage regular (for example, once a week on Fridays) online meetings for half an hour for conversations on everyday topics. A series of online stress management and neurographics courses could be launched to teach employees how to help themselves under stress. Case study: a Chinese Internet technology company has set up a 24-hour emergency counselor and psychologist service for all telecommuting workers (including interns) and their families, as well as a distance learning course on emotion management during quarantine and COVID-19 pandemic [15].

Often, an employee does not have the opportunity to organize an isolated workplace at home, since many live in small apartments, some have small children who find it difficult to explain that mom or dad are working now. In this case, the remote work format turns out to be quite difficult and requires very high self-discipline from the employee. In any case, it is recommended to equip the most equipped workplace so that everything is at hand, and households can go about their business without interfering or distracting with questions. If the house is noisy, you can use headphones or earplugs. Some employees can use the help of the ritual of "imitation of the office", when they put on "formal clothes" in the morning, tea or coffee during the day is brewed only in a separate "office mug", etc. That is, to attach specific activities to objects and places at home: work only at a laptop, dine at the kitchen table, and only relax on the couch, without mixing these chains with each other. This can help emphasize work-home separation at the start and end of the work day.

You can also recommend that employees adhere to the following rules when working remotely:

- monitor your biorhythms and pay attention to which hours the activity is maximum - during these hours you can complete the maximum number of tasks;

Take time out of work, eat well, and do physical exercises during the breaks (some companies encourage healthy habits, for example, by linking to videos that promote physical and mental well-being, and by encouraging the use of fitness applications and services;

- while working at the computer, remove the smartphone as far as possible so that there is no temptation to look into social networks or be distracted by chats with friends;

- adjust the dim monitor screen, give rest to the eyes and do special exercises for the eyes;

during a break, if possible, go for a short walk near your home and try not to scroll through tasks in your head or look into your phone and work chats at this time.

When studying the factors affecting the development of human potential, the predominance of relatively directive management methods at the level of line managers of the enterprise was noted. This management style can be very effective when a crisis occurs in the company, as well as for newcomers or employees with a rather low level of professional maturity. Then the manager sets the task with maximum detail, stage by stage describes what exactly needs to be done. His instructions and orders are subject to strict execution by his subordinates $[4,16]$.

In view of the active phase of growth and development of companies and the sufficient professional maturity of the team of employees, it is proposed to more actively use the coaching approach in personnel management as a method of increasing human potential. Coaching is a well-established business technology. Today this technique is successfully applied in business and management. With its help, modern leaders unleash the potential of 
both the entire team and each team member, which ultimately helps to awaken the internal motivation of employees and achieve maximum efficiency of each individual, overcoming obstacles and making optimal use of resources. A coach does not solve problems for a person, but only by observing a sequence of certain actions directs a person so that he independently finds the most beneficial solutions for himself and for the organization.

The task of a leader using a coaching approach is to motivate the employee to bring his idea to life, to support him.

At the same time, the use of a leader as a coach will bring success only if a certain number of conditions are met:

- $\quad$ relations of mutual trust, respect and mutual understanding are established between the coach and the ward;

- $\quad$ both parties feel responsible for the result they are striving for;

- $\quad$ both the coach and his student have a great desire to learn and improve;

- the coach will try to be as impartial as possible (although in reality it can be difficult to get rid of the influence of his point of view).

Thus, the use of coaching in work with personnel allows you to reach a qualitatively new level of interaction and make progress in improving the professional skills of each employee. All this will greatly contribute to increasing the motivation of personnel and the disclosure of human potential in order to maximize its efficiency, which in the end should have a positive effect on the effectiveness of the entire business.

In order to develop human potential, it is recommended to implement a comprehensive training and development program for personnel, including both various advanced training programs for production workers, and seminars and trainings for office and "field" employees. For the first category of workers, an assessment of the effectiveness of training is a quite measurable indicator - the result of an exam after mastering a new / related profession, increasing the category or mastering a new type of equipment. At the same time, it turns out to be quite difficult to measure the effectiveness and efficiency of the second type of training. However, evaluation is necessary to ensure the effectiveness of the process, because if the training is not evaluated in any way, then it is difficult to prove that it turned out to be useful, and then also convince others that money should be further invested in this direction.

Learning effectiveness is a measurable business benefit. A large number of factors influence the effectiveness of training: the motivation of employees, the professionalism of the trainers, the correspondence of the training program to the customer's needs, pretraining diagnostics, the number of people in the group, the optimal balance of theory and practice, etc.

Assessment of the effectiveness of training makes it possible to:

- answer the question of whether the choice of the training organization / trainer was right;

- $\quad$ to assess how the advanced training of employees affects the quality and dynamics of the enterprise's development;

- monitor the skills and abilities of employees, growth / decline of the level of their competencies;

- help to achieve a greater economic effect of the organization's activities.

To assess the effectiveness of training, you can use a fairly well-known four-level model proposed in 1959 by Donald Kirkpatrick, which is now classical.

This model is built on 4 levels for assessing the effectiveness of personnel training:

Level 1 - Assessment of the participants' reaction to the training program.

At this level, through a questionnaire, the assessment of the training by its participants is recorded: their emotional state, attention and interest in the topic of training, opinion 
about the quality of the training (usefulness, the work of the trainer, the level of complexity of the material and exercises, etc.).

The results of the questionnaire are usually used by the training organizers to assess the correct choice of the training topic and the level of the trainer's work.

2nd level - assessment of knowledge and experience gained by participants in the training program.

At this level, it is assessed to what extent the knowledge and skills of the participants have been assimilated, which they can apply during their work. It traditionally uses assessment methods such as professional and behavioral tests, thematic questionnaires, control exercises, observation, etc., according to the results of which the participants are given marks or points.

The results of the assessment at this level are important both for the participants (to quantify the progress in the acquired knowledge) and for the trainer (how effective the chosen teaching strategy and methods were).

3rd level - assessment of the level of behavior in the workplace.

At this level of assessment, we mean the practical results of the training: are the knowledge, skills and attitudes acquired by the participants used / implemented in work situations (as opposed to educational ones) and how effectively they are used in professional activities. This stage is one of the most difficult to assess, since the effect of training is usually not noticeable immediately. Therefore, this type of assessment is carried out only some time after the completion of the training, when the participants will be able to practice applying new knowledge and skills in the workplace. The direct supervisors of the training participants are necessarily involved in this stage of the assessment.

To compare the new work behavior with the previous one (or with the established corporate standards), both formal methods (qualification exam, certification, performance of control tasks in the workplace) and informal methods (structured observation, keeping work diaries, etc.) are used.

4th level - evaluation of results.

At this level, the impact of the learning outcomes on the activities and / or financial results of the entire organization is assessed. Key business metrics are identified, which are indicators of the effectiveness of training (increased productivity, improved quality, reduced staff turnover, etc.). At the same time, it is important to know the exact data of these indicators before training, since only those changes that have occurred after the training of employees are related to the results.

Collecting this kind of information requires serious analytical work, time, financial resources and coordinated efforts of many departments of the company. Therefore, this level of assessment is not used for individual typical trainings. It makes sense to use this tool to assess the business effect of expensive complex training programs $[9,12]$.

\section{Discussion of results}

Taking into account the commensurability of labor costs for assessing the effectiveness of training and the corresponding business effect, it can be concluded that according to the $1 \mathrm{st}$ level of the Kirkpatrick model, it is advisable to evaluate $80-100 \%$ of the programs, according to the 2 nd $-40-60 \%$, according to the 3 rd $-30 \%$, on the 4 th $-10-20 \%$.

If you try to integrate the Kirkpatrick model to assess the effectiveness of training, you can propose the following algorithm of actions:

For the 1st level of assessment, which is usually used immediately upon completion of the training, several methods can be proposed.

DISCUSSION. Group discussion, in which the trainer identifies the feedback structure (for example, what was useful at the event, whether the participants' expectations from the 
training were met, was there enough theory / practice, etc.) After that, everyone takes turns expressing their point of view, and the trainer captures information for consolidation. This format is quite emotional and makes it possible to quickly get feedback.

QUESTIONNAIRE. Participants fill out a questionnaire with a standardized set of questions, including the following aspects: the usefulness of the acquired knowledge and skills, the quality of the presentation of the material, the level of complexity of the exercises, the informativeness of the handouts, the optimal balance of theory and practice, the level of the coach's work, etc. The data of the questionnaires are usually quite rational and informative.

DARTS. A method of visualizing assessments, in which a classic target is depicted on a flipchart, divided into sectors with a marker, reflecting the aspects described above. Participants mark on the target crosses corresponding to their assessment of each parameter. This methodology allows you to get a visual informative picture of the assessment of the training: in what aspects the training has achieved the goal, and in what aspects missed the target. This method of group rapid assessment is used when there is a shortage of time, when there is very little time left for summing up the results.

For the 2nd level of assessment, you can also offer the TESTING methodology. Tests with questions on the topic of the training are prepared in advance. Participants take a test before and after training, based on a comparison of the results, a conclusion is made about their assimilation of the material.

For the 3rd level of assessment, which implies the degree of application in practice of the knowledge gained and their transformation into skills, the Method 360 can be used when managers, subordinates and colleagues of an employee fill out a questionnaire about changes in his behavior in the workplace due to the application of new knowledge and skills. This method appeared back in the 1980s. as a complement to the method of personnel assessment through management by objectives. The organization of this method requires some effort, however, specialists in the field of personnel assessment define it as one of the most progressive.

It should be noted that in order for the skills to become skills, they must be repeated at least 21 times. Therefore, it is advisable to use this level of assessment no earlier than 1-2 months after the training.

To consolidate the acquired knowledge and skills, it is possible to instruct employees who have undergone training, conduct mini-presentations using the material covered for colleagues from other departments, or participate in the adaptation and training of new employees. There is no better way to properly learn something than to try to teach it to another.

It is also recommended for employees to suggest improving any business processes using the information obtained during the training. An employee can submit for the management's consideration his proposals for improving the activities of both the employee himself and the organization as a whole (for example, an action plan to improve any direction of the company's activities, creating a new work standard, developing and implementing a project, improving or optimizing a business process etc.).

The 4th level of assessment is the most difficult, since it is necessary to identify, formulate and evaluate key performance indicators (KPIs), which are potentially influenced by learning outcomes.

These business indicators of the company include: improving quality, reducing the number of complaints or customer complaints, increasing labor productivity, increasing production rates, reducing costs, reducing staff turnover, increasing sales, developing new market segments, reducing financial costs, reducing the number of accidents and industrial injuries, reduced customer service time, reduced production costs, fewer conflicts, etc. 
The list of KPIs for assessing learning outcomes are selected individually in each specific situation, taking into account the topic of the training, the relevance of the business indicator and the goals of the company.

In conclusion, I would like to emphasize that organizing a training system is not enough. It is also necessary to ensure that employees use the acquired knowledge and skills in practice in their work, only then the results of training will be development and investments will be justified.

\section{Conclusion}

It has been found that of all organizational resources, it is human potential that hides the greatest reserves for increasing the efficiency of an organization and its economic security, since the company's profitability, its capitalization, an increase in the share of intangible assets and other business results directly depend on the competence and correctness of employees' actions. Therefore, one of the main tasks is the selection of qualified personnel with high potential, its effective use and development, as well as minimization of risks and threats from employees.

The main directions of personnel policy when working with high-potential employees and effective tools for their development and motivation have been determined. The main goals and approaches for the formation of the training system are outlined: providing employees with the necessary knowledge and skills and their constant support at a high level; preparation of employees for promotion or replacement of colleagues during their absence; maintaining employee engagement and a positive attitude towards work.

Instruments are proposed to improve measures for the development of human potential, contributing to an increase in the level of economic security of the enterprise. Also, proposals aimed at reducing the risk of burnout of remotely working employees, the introduction of a coaching approach in personnel management, proposals for improving the system for assessing the effectiveness of employee training.

Thus, the procedures for the development of human potential, in order to ensure the economic security of the enterprise, are primarily aimed at continuous work with the employees of the company as a whole, individual employees to increase the status and loyalty of the company, to form a team spirit based on common values and interests.

\section{References}

1. D. Burkaltseva, O.Reznikova, S.Plaksa, Economic security: conflict in the organization 7(2)(2020)

2. D. Kechek,I. Polgar, Overview of operational research in Croatia (2020)

3. H. Gardner, About Human Potential: A 40-Year Saga(2020)

4. D. Y. Dai, Magazine for the education of the gifted(2020)

5. T.E.Davydova, E.A. Avdeeva, T.I.Makeeva,2nd international scientific conference of Volgograd state University at a competitive, sustainable and secure development of the regional economy (CSSDRE) (2019)

6. N.V.Latova,Sociological research(2019)

7. S.I.Babina, A.Y. Nesterov, I.Y.Sadovnikova, 2nd International Scientific Conference of Volgograd State University on Competitive, Sustainable and Safe Development of the Regional Economy (CSSDRE) (2019)

8. O.V.Loseva, N.M. Abdikeev, M.V. Melnichuk,Revista Inclusions(2020) 
9. E.N.Klochko,A.A.Adamenko, O.V.Brizhak,2nd International Scientific Conference of Volgograd State University on Competitive, Sustainable and Safe Development of the Regional Economy (CSSDRE) (2019)

10. N.Sirotkina, V.Mishchenko, A. Kazartseva,33rd Conference of the International Association of Business Information and Management (IBOMA) (2019)

11. G. Tokatly, M.C. Dorneich, 38th IEEEAIAA Conferenc e on Digital Avionics Systems (DASC) (2019)

12. Ya. Epifanova, I.Dzhedzhula, International scientific electronic Journal «Economics of Agriculture and Resources» (2020)

13. S. Moran, Magazine for the education of the gifted(2020)

14. Ya. Rudskaya, S. Kuznetsov, P.Salnikova,34th Conference of the International Association of Business Information and Management (IBOMA) (2019)

15. L. Boronina, A. Balyasov, I. Visnevsky, The 13th International Days of Statistics and Economics (2019)

16. Z.Zhivko, Ya.Gorban, M. Korzh, Management theory and research for the development of rural business and infrastructure (2020) 